\title{
Children's Internal Attributions of Anxiety-Related Physical Symptoms: Age-Related Patterns and the Role of Cognitive Development and Anxiety Sensitivity
}

\author{
Peter Muris • Birgit Mayer • Nancy Kramer Freher • \\ Sylvana Duncan · Annemiek van den Hout
}

Published online: 4 May 2010

(C) The Author(s) 2010. This article is published with open access at Springerlink.com

\begin{abstract}
The present study examined age-related patterns in children's anxiety-related interpretations and internal attributions of physical symptoms. A large sample of 388 children aged between 4 and 13 years completed a vignette paradigm during which they had to explain the emotional response of the main character who experienced anxietyrelated physical symptoms in a variety of daily situations. In addition, children completed measures of cognitive development and anxiety sensitivity. Results demonstrated that age, cognitive development, and anxiety sensitivity were all positively related to children's ability to perceive physical symptoms as a signal of anxiety and making internal attributions. Further, while a substantial proportion of the younger children (i.e., $<7$ years) were able to make a valid anxiety-related interpretation of a physical symptom, very few were capable of making an internal attribution, which means that children of this age lack the developmental prerequisites for applying physical symptoms-based theories of childhood anxiety.
\end{abstract}

Keywords Anxiety-related physical symptoms · Internal/external attributions · Anxiety sensitivity · Children

\section{Introduction}

Anxiety is a normal phenomenon during childhood and although most forms of anxiety are mild and transient in nature, it is also true that in a substantial minority of the children anxiety becomes so severe and persistent that it takes the form of an anxiety disorder [1]. Epidemiological studies have indicated that with a prevalence rate of around 5\%, anxiety disorders are among the most common types of psychopathology among children [2]. With this in mind, the study of childhood anxiety and its developmental antecedents seems certainly relevant and important [3]. In spite of the fact that research on childhood anxiety

P. Muris $(\bowtie) \cdot$ B. Mayer · N. K. Freher $\cdot$ S. Duncan · A. van den Hout Institute of Psychology, Erasmus University Rotterdam, P.O. Box 1738, 3000 Rotterdam, The Netherlands

e-mail: muris@fsw.eur.nl 
has steadily increased and achieved significant advancements during the past decades [4], there are still a number of issues that have been relatively understudied and therefore require further scientific exploration. One of these topics is concerned with children's perception and interpretation of the physical symptoms that accompany anxiety.

According to the three-systems model of Lang [5], the emotion of anxiety not only manifests itself in subjective feelings and thoughts and observable fight-flight-freeze behavior, but also in physical symptoms such as palpitations, trembling, and shortness of breath. In the adult literature, several theories have been formulated that not only view physical symptoms as a concomitant feature of anxiety but rather assume them to play a role in the formation of anxiety pathology. For instance, the cognitive account of panic [6] postulates that catastrophic interpretations of physical symptoms are the vehicle behind the occurrence of panic attacks. Briefly, such catastrophic interpretations involve the perception of these symptoms as far more threatening than they actually are. That is, palpitations may be interpreted as a sign of an impeding heart attack, trembling may be perceived as signaling loss of control, whereas shortness of breath may be seen as the cessation of breathing and death. Clearly, such interpretations will elicit further anxiety and lead to an intensification of the physical symptoms. In this way, the individual becomes trapped in a vicious circle which eventually culminates in a full-blown panic attack. Another example involves the theory on anxiety sensitivity, which refers to the habitual tendency to become fearful of anxiety-related physical symptoms because they may have potentially harmful somatic and/or psychological consequences. Individuals who display high levels of anxiety sensitivity would be more vulnerable to develop panic and other anxiety disorders [7]. Altogether, these theories assume that anxiety problems may arise when people make internal attributions of their physical symptoms, which means that they reflect on the negative implications that such symptoms may have for themselves (i.e., thoughts of losing control, going crazy, becoming really sick or even dying).

There is still debate on the issue to what extent these physical symptoms-based theories are applicable to youths. There are indications that the cognitive model of panic [8] and the anxiety sensitivity account [9] are applicable to adolescents, but it remains unclear whether such theories can be generalized to younger children. In an older review article, Nelles and Barlow [10] are rather skeptical in this respect as they argue that younger children (a) are less capable of recognizing and experiencing the physical symptoms of anxiety, and (b) lack the cognitive capacity to make internal attributions of such physical symptoms, which are thought to play a central role in both the cognitive theory of panic and the anxiety sensitivity account.

More than two decades later, the empirical exploration of these arguments is still limited. Available studies have indicated that from the age of 7, children are increasingly able to understand physical symptoms and to link such symptoms to the emotional state of anxiety [11], and that this is particularly true when their cognitive abilities are more matured $[12,13]$. Research on developmental progression of children's ability to make internal attributions is extremely sparse. To the current authors' knowledge there is only one investigation that has directly addressed this issue. In that study, Mattis and Ollendick [14] employed a guided imagery task to explore children's and young adolescents' interpretation of anxiety-related physical symptoms. Results indicated that the youths were capable of making internal attributions of such symptoms, although it should be mentioned that these cognitions were fairly concrete and frequently had to do with contracting a disease or dying rather than with more abstract psychological themes such as losing control and going crazy. No developmental trends were observed: the youngest children 
(mean age: 9 years) were equally able to make internal attributions as the oldest youths (mean age: 14 years) in this sample.

As the youngest participants in the Mattis and Ollendick [14] study on average were already 9 years old, this research remains silent about the minimum age at which children can interpret physical symptoms in an internal, catastrophic way. It can be hypothesized that again the age of 7 is an important transition point in this regard, as developmental psychologists assume that children then reach such an advanced level of cognitive maturation that they are increasingly able to link physical symptoms to anxiety and to consider these not only in the light of external danger but also within a context of internal threat [15, see also 16]. With this in mind, the present investigation was conducted to further explore age-related trends in children's ability to make internal attributions of anxietyrelated physical symptoms. A large sample of non-clinical children aged between 4 and 13 years were exposed to vignettes in which the main character experienced physical symptoms, and asked to tell what was happening in each of the situations. A qualitative analysis of children's accounts made it possible to examine to what extent children of various ages are able to relate physical symptoms to anxiety, and whether they make external or internal attributions for such symptoms. A theory-of-mind test and an anxiety sensitivity index were also administered to the children to investigate whether children's level of cognitive development and fear were associated with anxiety-related interpretations and (internal) attributions of physical symptoms.

\section{Methods}

\section{Participants}

Participants were 388 children (187 boys and 201 girls) recruited from five regular primary schools in the western part of The Netherlands. None of the children in the present study had participated in our previous research on the interpretation of anxiety-related physical symptoms [11-13]. Informed consent was obtained from children's parents before the study started; $42.6 \%$ of those invited agreed to participate. The ages of the children ranged between 4 and 13 years, with a mean age of 8.11 years $(\mathrm{SD}=2.48)$. To study age-related patterns, children were divided into three groups: (1) children aged 4-6 years $(n=111 ; 61$ boys and 50 girls), (2) children aged $7-9$ years $(n=146 ; 68$ boys and 78 girls), and (3) children aged $10-13$ years ( $n=131 ; 58$ boys and 73 girls). This division was primarily based on theories of cognitive development, which assume that around the age of 7 years important cognitive transitions occur [15]. Further, to examine trends in children after the age of 7, the 7- to 13-year-olds were divided into two roughly equal age groups. The vast majority of the children (94.3\%) was from original Dutch descent (i.e., Caucasian). The other children had an Arabic, Mediterranean, Moroccan, or Turkish background.

\section{Assessment}

\section{Anxiety-Related Interpretations and Attributions of Physical Symptoms}

Children were presented with 10 vignettes that were developed by the first author and successfully employed in previous studies on children's understanding and interpretation 
of anxiety-related physical symptoms [11-13]. Vignettes described everyday situations (e.g., "Sam walks with his/her friends to the playground") during which the main character experiences an anxiety-related physical symptom (i.e., hands trembling, sweating, difficulties with breathing, strange feeling in chest, heart beating very fast, feeling very warm, unpleasant feeling in head, feeling nauseous, feeling very dizzy, and unpleasant feeling in belly). To make the vignettes more understandable, especially to the younger children, each vignette was illustrated by a black-and-white drawing (see Appendix). The main character in the picture did not have a face and after hearing the vignette, children were asked to choose one of five cards displaying the (gender-non-specific) face of the character in five expressions reflecting the target emotion of anxiety and the alternative feelings of happiness, sadness, anger, and pain, by asking "Can you tell how Sam feels in this picture? What is the face that fits best?" After children had chosen an emotion, they were asked to briefly explain what was happening in the picture in order to check whether they were able to substantiate their choice. Two variables were derived from this vignette task: (1) the number of anxiety-related interpretations, i.e., physical symptoms that were (validly) linked to the emotion of anxiety, and (2) the number of internal/external attributions, i.e., whether children's account of what was happening reflected an internal (i.e., children indicated that the physical symptom reflected some kind of bodily/mental problem) or an external (i.e., children attributed the physical symptom to a threatening stimulus or situation in their environment) threat. Table 1 lists examples of attributions made by children in response to scenarios including various types of physical symptoms. The inter-rater reliability of these variables was investigated by asking an independent rater to score the responses of 203 children (i.e., $>50 \%$ ). For anxiety-related interpretations, the mean percentage of agreement was $92.2 \%$, with an average kappa of .81. For the internal/ external attributions variable, these figures were $97.6 \%$ and .82 , respectively. These favorable indices are in keeping with previous research showing that this vignette procedure can be reliably employed in children as young as 4 years [11-13].

\section{Cognitive Development}

A shortened version of the Theory-of-mind (TOM) test [17] was used that consisted of nine vignettes, stories, and drawings about which a child has to answer a total of 27 questions pertaining to various aspects of this socio-cognitive ability: recognition of emotions (e.g., "Who in this picture is angry?"), pretense (e.g., "Do as if you are feeling cold"), first-order beliefs (which refer to what children think about real events; e.g., "Michael thinks that Sophie is angry"), second-order beliefs (which pertain to what children think about other people's thoughts; e.g., "Josh thinks that Nicole thinks that he is angry with her"), understanding false beliefs (taking into consideration that an other person may have wrong information about a stimulus or situation; e.g., 'Sally and Ann' or 'Smarties' test), and understanding jokes, wordplays, and humor (see [17] for concrete examples). Each item of the test is scored as either failed (0) or passed (1). Accordingly, total TOM-test scores (Cronbach's $\alpha=.85$ ) range between 0 and 27, with higher scores indicating a more advanced theory-of-mind. The TOM-test is a reliable and valid measure of theory-of-mind that can be used in children aged 4 years and above. The instrument has sufficient to good internal consistency, test-retest stability, interrater-reliability, and discriminates between normal children and children with a pervasive development disorder, which are known to display deficits in this cognitive domain [17]. 
Table 1 Examples of non-anxiety interpretations and internal and external threat attributions (i.e., anxietyrelated interpretations) made by the children in relation to various types of physical symptoms

\begin{tabular}{|c|c|c|c|}
\hline \multirow{2}{*}{$\begin{array}{l}\text { Physical } \\
\text { symptom }\end{array}$} & \multirow{2}{*}{$\begin{array}{l}\text { Non-anxiety } \\
\text { interpretation }\end{array}$} & \multicolumn{2}{|l|}{ Anxiety-related interpretation } \\
\hline & & External threat attribution & Internal threat attribution \\
\hline Hands trembling & It is very cold in the room & $\begin{array}{l}\text { Sam is watching a scary } \\
\text { movie on TV }\end{array}$ & $\begin{array}{l}\text { There is something very } \\
\text { wrong with his hands }\end{array}$ \\
\hline Sweating & Sam has been sunbathing & $\begin{array}{l}\text { Sam expects to be punished } \\
\text { by mother }\end{array}$ & Sam has a serious fever \\
\hline $\begin{array}{l}\text { Difficulties with } \\
\text { breathing }\end{array}$ & Sam has played football & $\begin{array}{l}\text { Sam's homework is too } \\
\text { difficult }\end{array}$ & Sam is afraid of choking \\
\hline $\begin{array}{l}\text { Strange feeling } \\
\text { in chest }\end{array}$ & $\begin{array}{l}\text { Sam is wearing too many } \\
\text { sweaters }\end{array}$ & $\begin{array}{l}\text { Somebody has hit Sam on } \\
\text { the breast }\end{array}$ & Sam's heart stops beating \\
\hline $\begin{array}{l}\text { Heart beating } \\
\text { very fast }\end{array}$ & Sam has been running & Sam hears scary noises & Sam is having a heart attack \\
\hline $\begin{array}{l}\text { Feeling very } \\
\text { warm }\end{array}$ & $\begin{array}{l}\text { Sam is sitting near the } \\
\text { heating }\end{array}$ & Sam is reading a scary book & Sam is not feeling well \\
\hline $\begin{array}{l}\text { Unpleasant } \\
\text { feeling in head }\end{array}$ & $\begin{array}{l}\text { Too many children want } \\
\text { to play with him }\end{array}$ & $\begin{array}{l}\text { Sam is afraid that other } \\
\text { children laugh about him }\end{array}$ & $\begin{array}{l}\text { There is something seriously } \\
\text { wrong in his head }\end{array}$ \\
\hline $\begin{array}{l}\text { Feeling } \\
\text { nauseous }\end{array}$ & $\begin{array}{l}\text { Sam prefers to stay at } \\
\text { home }\end{array}$ & $\begin{array}{l}\text { Sam has eaten something } \\
\text { wrong }\end{array}$ & Sam is afraid of throwing up \\
\hline $\begin{array}{l}\text { Feeling very } \\
\text { dizzy }\end{array}$ & $\begin{array}{l}\text { Sam has made too many } \\
\text { spins }\end{array}$ & $\begin{array}{l}\text { Sam has fallen from the } \\
\text { couch }\end{array}$ & Sam is afraid of fainting \\
\hline $\begin{array}{l}\text { Unpleasant } \\
\text { feeling in } \\
\text { belly }\end{array}$ & $\begin{array}{l}\text { Sam is in love with } \\
\text { somebody }\end{array}$ & Sam is afraid of ghosts & $\begin{array}{l}\text { Sam is afraid that he is really } \\
\text { sick }\end{array}$ \\
\hline
\end{tabular}

\section{Anxiety Sensitivity}

Anxiety sensitivity, which can be defined as fear of anxiety-related physical symptoms, was assessed by means of a brief interview, during which children were asked to indicate how fearful they would be when experiencing the 10 physical symptoms that also featured in the vignettes, e.g., "How scared would you feel when your heart is beating fast?" These fear ratings had to be given on a visual scale depicting Koala bears showing no fear (1), some fear (2), and a lot of fear (3) [18]. A total anxiety sensitivity score (Cronbach's $\alpha=.73$ ) was obtained by summing children's ratings on all items. This interview measure was preferred above the well-known and widely used Childhood Anxiety Sensitivity Index [19] which can reliably be used from age 7 and hence was considered as too difficult for the younger children in our sample.

\section{General Anxiety}

Children's general anxiety level was measured by means of the Preschool Anxiety ScaleRevised (PAS-R) [20], which is a modification of the Preschool Anxiety Scale (PAS) [21]. This parent-based questionnaire includes 30 items representing symptoms of social phobia, generalized anxiety, separation anxiety, specific fears, and obsessive-compulsive disorder. Parents were asked to score the anxiety symptoms of their child on a 5-point scale, ranging from 1 (not at all true) to 5 (very often true). In the present study, we only used the PAS-R total score (Cronbach's $\alpha=.90$ ), which can be calculated by summing the scores on all 
items. Psychometric evaluations of the original PAS and PAS-R have shown that these questionnaires display good reliability and validity [20,21], and this appears also true when they are employed in older children [22].

Procedure

Children's parents were contacted by means of a letter explaining the purpose of the study, inviting them to participate, and if they agreed to do so to complete the PAS-R as an index of their child's general anxiety level. Children who were allowed to participate were tested individually in a separate room at school by a trained research assistant. First, the vignette test was administered. The experimenter started by showing the pictures of the five basic emotions, and if necessary explained them to the children by providing clear-cut examples $[12,13]$. Vignettes were administered in a counter-balanced fashion in order to minimize unintended order effects. Next, children were tested with the TOM-test, after which the anxiety sensitivity interview was conducted. Finally, children were given a small present as a thank-you in return for their participation.

\section{Results}

\section{General Findings}

Before discussing the main results of the present study, a number of general findings are addressed. First of all, as expected, there was a substantial positive relationship between age and cognitive development as indexed by the TOM-test $(r=.75, p<.001)$. To inspect this result in more detail, an analysis of variance was performed comparing the TOM-test scores across the three age groups. This analysis indicated that cognitive development showed a steady progression as children became older, with mean scores being 14.50 $(\mathrm{SD}=4.27)$ for 4 - to 6-year-olds, $20.60(\mathrm{SD}=3.10)$ for 7 - to 9-year-olds, and 23.31 $(\mathrm{SD}=3.03)$ for 10 - to 13 -year-olds $[F(2,385)=202.43, p<.001$; for all post-hoc comparisons, $p<.001]$. Second, a small but significant positive correlation was observed between general anxiety as indexed by the PAS-R completed by the parents and anxiety sensitivity as assessed during a brief interview with the children $(r=.25, p<.001)$, which indicates that there was some shared variance among these two anxiety measures. Third, significant gender differences were only found for childhood anxiety measures: as could be expected, girls displayed higher levels of general anxiety (means being 61.80, $\mathrm{SD}=16.06$ versus 56.91, $\mathrm{SD}=14.23$ ) and anxiety sensitivity (means being $17.53, \mathrm{SD}=3.85$ versus $16.30, \mathrm{SD}=3.71$ ) than did boys [both $t(386) \geq 3.14, p<.01$ ]. Additional comparisons revealed that this gender difference in anxiety scores showed itself in all age groups.

\section{Anxiety-Related Interpretations and Attributions of Physical Symptoms}

Percentages of children who provided an anxiety-related interpretation of various types of physical symptoms are shown in Table 2. As can be seen, "hands trembling", "sweating", and "difficulties with breathing" were the symptoms that were most frequently associated with anxiety. Further, a comparison of the percentages of children across the three age groups who linked anxiety to various types of physical symptoms revealed clear-cut agerelated patterns for "hands trembling", "sweating", "difficulties with breathing", "heart 
Table 2 Percentages of children in the total sample and the three age groups who provided an anxietyrelated interpretation of various types of physical symptoms

\begin{tabular}{|c|c|c|c|c|c|}
\hline $\begin{array}{l}\text { Physical } \\
\text { symptom }\end{array}$ & $\begin{array}{l}\text { Total group } \\
(N=388)\end{array}$ & $\begin{array}{l}\text { 4- to 6-year-olds } \\
(n=111)\end{array}$ & $\begin{array}{l}\text { 7- to 9-year-olds } \\
(n=146)\end{array}$ & $\begin{array}{l}\text { 10- to } 13 \text {-year-olds } \\
(n=131)\end{array}$ & $\chi^{2}$ \\
\hline Hands trembling & 35.6 & $16.2_{\mathrm{a}}$ & $37.0_{\mathrm{b}}$ & $50.4_{\mathrm{c}}$ & $30.81 * * *$ \\
\hline Sweating & 28.9 & $6.3_{\mathrm{a}}$ & $32.2_{\mathrm{b}}$ & $44.3_{\mathrm{c}}$ & $43.45^{* * *}$ \\
\hline $\begin{array}{l}\text { Difficulties with } \\
\text { breathing }\end{array}$ & 28.6 & $19.8_{\mathrm{a}}$ & $24.7 \mathrm{a}$ & $40.5 \mathrm{~b}$ & $14.32 * *$ \\
\hline $\begin{array}{l}\text { Strange feeling } \\
\text { in chest }\end{array}$ & 23.7 & 22.5 & 19.9 & 29.0 & 3.31 \\
\hline $\begin{array}{l}\text { Heart beating } \\
\text { very fast }\end{array}$ & 19.6 & $10.8_{\mathrm{a}}$ & $25.3_{\mathrm{b}}$ & $20.6_{\mathrm{b}}$ & $8.59^{*}$ \\
\hline $\begin{array}{l}\text { Feeling very } \\
\text { warm }\end{array}$ & 15.2 & $6.3_{\mathrm{a}}$ & $14.4_{b}$ & $23.7_{\mathrm{c}}$ & $14.16^{* *}$ \\
\hline $\begin{array}{l}\text { Unpleasant } \\
\text { feeling in head }\end{array}$ & 13.9 & $7.2_{\mathrm{a}}$ & $13.7_{\mathrm{ab}}$ & $19.8_{\mathrm{b}}$ & $8.02 *$ \\
\hline Feeling nauseous & 13.4 & 17.1 & 11.6 & 12.2 & 1.89 \\
\hline $\begin{array}{l}\text { Feeling very } \\
\text { dizzy }\end{array}$ & 11.3 & 11.7 & 12.3 & 9.9 & 0.42 \\
\hline $\begin{array}{l}\text { Unpleasant } \\
\text { feeling in belly }\end{array}$ & 10.1 & 10.8 & 7.5 & 12.2 & 1.77 \\
\hline
\end{tabular}

Row percentages that do not share similar subscripts differ at $p<.05$

$* p<.05, * * p<.01, * * * p<.001$

beating very fast", "feeling very warm", and "unpleasant feeling in head" $\left[\right.$ all $\chi^{2}(2) \geq$ $8.02, p<.05]$. In general, with increasing age, these symptoms were more frequently interpreted as a sign of anxiety.

Table 3 displays percentages of children in the three age groups who made internal and external attributions in relation to various types of physical symptoms. For almost all physical symptoms, the percentage of internal attributions gradually increased with age [with $\chi^{2}(2) \geq 6.02, p<.05$ ]. Interestingly, for some physical symptoms this increase appeared to occur at an earlier age (e.g., "heart beating fast", "feeling very warm"), while for other symptoms this growth seemed to take place at a later age (e.g., "difficulties with breathing", "feeling very dizzy"). Percentages of children making external attributions were fairly stable across the three age groups. In case a significant age trend was observed (i.e., "strange feeling in chest" and "feeling nauseous"), it was found that with increasing age children made less external attributions in relation to physical symptoms $\left[\chi^{2}(2)\right.$ being $14.89, p<.001$ and $12.18, p<.01$, respectively].

Figure 1 provides an overview of the age-related patterns as observed for anxietyrelated interpretations and internal/external attributions of physical symptoms. Note that the average number of physical symptoms that were associated with anxiety steadily increased as children became older $[F(2,385)=26.85, p<.001$; for all post-hoc comparisons, $p<.01]$, and that this was entirely due to the increase in the number of internal attributions $[F(2,385)=33.15, p<.001$; for all post-hoc comparisons, $p<.01]$, whereas the number of external attributions remained fairly stable across the three age groups $[F(2,385)=1.22, p=.30]$. 
Table 3 Percentages of children across the three age groups who made an internal or external attribution in relation to various types of physical symptoms

\begin{tabular}{|c|c|c|c|c|c|}
\hline Physical symptom & Attribution & $\begin{array}{l}\text { 4- to 6-year-olds } \\
(n=111)\end{array}$ & $\begin{array}{l}\text { 7- to } 9 \text {-year-olds } \\
(n=146)\end{array}$ & $\begin{array}{l}10 \text { - to } 13 \text {-year-olds } \\
(n=131)\end{array}$ & $\chi^{2}$ \\
\hline \multirow[t]{2}{*}{ Hands trembling } & Internal & $10.3_{\mathrm{a}}$ & $19.1_{\mathrm{ab}}$ & $30.3_{b}$ & $7.15^{*}$ \\
\hline & External & 35.9 & 41.6 & 43.8 & 0.70 \\
\hline \multirow[t]{2}{*}{ Sweating } & Internal & $0.0_{\mathrm{a}}$ & $9.7_{\mathrm{ab}}$ & $19.7_{\mathrm{b}}$ & $6.02 *$ \\
\hline & External & 38.9 & 66.1 & 62.0 & 4.41 \\
\hline \multirow{2}{*}{$\begin{array}{l}\text { Difficulties with } \\
\text { breathing }\end{array}$} & Internal & $11.9 \mathrm{a}$ & $27.7_{\mathrm{a}}$ & $66.7_{\mathrm{b}}$ & $34.03 * * *$ \\
\hline & External & 40.5 & 48.9 & 26.3 & 5.81 \\
\hline \multirow{2}{*}{$\begin{array}{l}\text { Strange feeling } \\
\text { in chest }\end{array}$} & Internal & $12.1_{\mathrm{a}}$ & $38.9_{b}$ & $73.2_{\mathrm{c}}$ & $28.20 * * *$ \\
\hline & External & $63.6_{a}$ & $41.7_{\mathrm{a}}$ & $19.5_{\mathrm{b}}$ & $14.89 * * *$ \\
\hline \multirow{2}{*}{$\begin{array}{l}\text { Heart beating } \\
\text { very fast }\end{array}$} & Internal & $18.2 \mathrm{a}$ & $43.8_{\mathrm{b}}$ & $56.7_{\mathrm{b}}$ & $7.83^{*}$ \\
\hline & External & 36.4 & 33.3 & 33.3 & 0.07 \\
\hline \multirow[t]{2}{*}{ Feeling very warm } & Internal & $5.0_{\mathrm{a}}$ & $34.3_{\mathrm{b}}$ & $38.5_{\mathrm{b}}$ & $7.62 *$ \\
\hline & External & 30.0 & 25.7 & 41.0 & 2.06 \\
\hline \multirow{2}{*}{$\begin{array}{l}\text { Unpleasant feeling } \\
\text { in head }\end{array}$} & Internal & 0.0 & 6.9 & 16.7 & 4.05 \\
\hline & External & 44.4 & 62.1 & 70.0 & 3.11 \\
\hline \multirow[t]{2}{*}{ Feeling nauseous } & Internal & $22.7_{\mathrm{a}}$ & $45.5_{\mathrm{ab}}$ & $59.1_{b}$ & $6.08 *$ \\
\hline & External & $63.6_{a}$ & $31.8_{\mathrm{b}}$ & $13.6_{\mathrm{b}}$ & $12.18^{* *}$ \\
\hline \multirow[t]{2}{*}{ Feeling very dizzy } & Internal & $8.7 \mathrm{a}$ & $11.1_{\mathrm{a}}$ & $60.0_{\mathrm{b}}$ & $17.11 * * *$ \\
\hline & External & 47.8 & 55.6 & 26.7 & 3.28 \\
\hline \multirow{2}{*}{$\begin{array}{l}\text { Unpleasant feeling } \\
\text { in belly }\end{array}$} & Internal & $4.0_{\mathrm{a}}$ & $47.1_{b}$ & $66.7_{\mathrm{b}}$ & $19.58 * * *$ \\
\hline & External & 44.0 & 17.6 & 22.2 & 4.09 \\
\hline
\end{tabular}

Percentages of internal and external attributions for each physical symptom do not add up to $100 \%$ as some children could not substantiate their anxiety-related interpretation. Row percentages that do not share similar subscripts differ at $p<.05 . * p<.05, * * p<.01, * * * p<.001$

\section{Effects of Anxiety and Cognitive Development}

To examine whether anxiety sensitivity and cognitive development had an impact on children's anxiety-related interpretations and internal/external attributions of physical symptoms, a series of regression analyses was carried out. In these analyses, age, gender, and general anxiety were also entered as additional predictors as this would make it possible to study the unique contributions of anxiety sensitivity and cognitive development beyond these relevant control variables. Before discussing the results of these analyses, it is important to note that collinearity statistics were inspected, which were all found to be within acceptable limits (i.e., for all predictor variables, tolerance (TOL) was $>.40$, whereas the variance of inflation (VIF) was <2.50). As can be seen in Table 4, the regression analysis predicting anxiety-related interpretations of physical symptoms yielded significant contributions of age, cognitive development, and anxiety sensitivity. In all cases betas were positive, which means that with increasing age, a more advanced cognitive development and higher levels of anxiety sensitivity, children more often made anxiety-related 
Fig. 1 Mean number of anxietyrelated interpretations and internal/external attributions of physical symptoms (standard errors are also shown) made by the children in various age groups

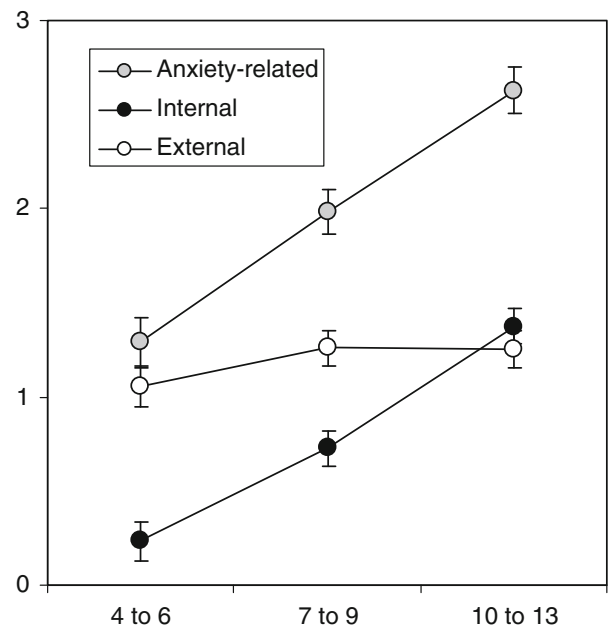

interpretations of physical symptoms. Additional analyses predicting attributions of physical symptoms revealed that this pattern of results was mainly carried by the internal attributions, for which almost identical results were found, whereas, for external attributions no significant predictors emerged. Note that the percentage of explained variance in anxietyrelated interpretations and internal attributions scores was significant $[F(5,376)$ being 16.59 and 16.81, respectively, $p<.001$ ] but rather modest (i.e., 18\%).

A final additional regression analysis was performed in which anxiety sensitivity scores were predicted from age, gender, cognitive development, and general anxiety levels (see Table 4). These predictor variables accounted for a significant proportion of the variance [i.e., 20\%; $F(4,377)=23.67, p<.001]$. Standardized betas for gender and general anxiety were positive, whereas those for age and cognitive development were negative. This means that a female gender and higher levels of general anxiety were associated with higher levels of anxiety sensitivity, while increasing age and cognitive development were accompanied by lower levels of anxiety sensitivity.

\section{Discussion}

The present study examined age-related patterns in children's anxiety-related interpretations and internal attributions of physical symptoms. For this purpose, a large sample of children aged between 4 and 13 years were tested by means of a vignette paradigm. Results indicated that even among the youngest children in our sample a substantial proportion was capable of perceiving physical symptoms as a signal of anxiety. More precisely, $69.4 \%$ of the 4- to 6-year-olds made a valid anxiety-related interpretation of at least one physical symptom, and this percentage further increased among 7- to 9- (82.9\%) and 10- to 13-yearolds $(95.4 \%)$ [11-13]. When looking at children's internal attributions, it should be noted that only a very small percentage of the 4 - to 6-year-olds $(16.2 \%)$ was capable of considering internal causes for the physical symptoms in the vignettes. In older children, internal attributions were clearly more often made, with percentages of $45.9 \%$ in 7 - to 9 -year-olds and $64.9 \%$ in 10- to 13 -year-olds. Thus, it can be concluded that prior to age 7 few children are able to relate physical symptoms to anxiety and to make internal 
Table 4 Results of regression analyses predicting anxiety sensitivity, anxiety-related interpretations and internal/external attributions of physical symptoms scores

\begin{tabular}{|c|c|c|c|c|}
\hline & $B$ & SE & $\beta$ & $\Delta R^{2}$ \\
\hline Anxiety-related interpretations & & & & $.18^{* * * *}$ \\
\hline Gender & 0.07 & 0.15 & .02 & \\
\hline Age & 0.16 & 0.04 & $.26^{* * *}$ & \\
\hline Cognitive development & 0.06 & 0.02 & $.21 * *$ & \\
\hline General anxiety & -0.00 & 0.01 & -.08 & \\
\hline Anxiety sensitivity & 0.05 & 0.02 & $.11^{*}$ & \\
\hline Internal attributions & & & & $.18 * * *$ \\
\hline Gender & -0.08 & 0.12 & -.03 & \\
\hline Age & 0.12 & 0.03 & $.25^{* * *}$ & \\
\hline Cognitive development & 0.05 & 0.02 & $.22 * *$ & \\
\hline General anxiety & -0.01 & 0.00 & -.09 & \\
\hline Anxiety sensitivity & 0.03 & 0.02 & $.11^{*}$ & \\
\hline External attributions & & & & .02 \\
\hline Gender & 0.15 & 0.12 & .06 & \\
\hline Age & 0.03 & 0.04 & .07 & \\
\hline Cognitive development & 0.01 & 0.02 & .05 & \\
\hline General anxiety & -0.01 & 0.00 & -.01 & \\
\hline Anxiety sensitivity & 0.01 & 0.02 & .04 & \\
\hline Anxiety sensitivity & & & & $.20 * * *$ \\
\hline Gender & 1.26 & 0.36 & $.17 * *$ & \\
\hline Age & -0.25 & 0.11 & $-.16^{*}$ & \\
\hline Cognitive development & -0.17 & 0.06 & $-.22 * *$ & \\
\hline General anxiety & 0.04 & 0.01 & $.17^{* *}$ & \\
\hline
\end{tabular}

$N=388$. Besides the vignette task that was employed to measure anxiety-related interpretations and internal/external attributions, the following scales were used: (a) Cognitive development: Theory-of-mind test (child), (b) General anxiety: Preschool Anxiety Scale-Revised (parent), and (c) Anxiety sensitivity: Interview (child)

$* p<0.05, * * p<0.01, * * * p<0.001$

attributions for such symptoms, whereas from that age an increasing number of children seem to possess such cognitive skills.

It should be noted that this study did not examine whether young people of various ages display panic-like symptoms but rather investigated to what extent children meet the developmental prerequisites for applying physical symptoms-based theories (i.e., the cognitive theory of panic and the anxiety sensitivity account). The idea is that when children are capable of relating physical symptoms to anxiety and making internal attributions about such symptoms, it will also be possible for them to have a panic attack [10]. However, it is questionable whether the mere presence of such cognitive abilities is sufficient to produce panic, as many other variables seem to be involved in the pathogenesis of this anxiety disorder (e.g., anxiety sensitivity, genetic vulnerability, parental modeling) [8].

The findings confirm the notion that from the age of 7, children are increasingly capable of making anxiety-related interpretations and internal attributions of physical symptoms. Apparently, and this was also confirmed by the developmental pattern in the current TOMtest data, children acquire important cognitive skills around that age, which significantly 
increase their comprehension of physical symptoms. This does not mean, however, that the ability to understand physical symptoms is closely associated with the transition to Piaget's [23] stage of concrete operations as suggested by several authors [16]. The present data indicate that the frequency of anxiety-related interpretations and in particular internal attributions of physical symptoms increased linearly as children became older. Obviously, this is in line with cognitive-biological oriented models which assume that cognitive development should be seen as a gradual accumulation of knowledge, skills, and information processing capacity that results in a continuous maturation of cognition [24].

In keeping with one of our previous studies [12], cognitive development as indexed by a theory-of-mind test accounted for a unique proportion of the variance in children's interpretation and internal attributions of anxiety-related physical symptoms. This is not surprising as the TOM-test includes various items referring to the recognition of emotions as well as the understanding of such mental states, and thus taps part of the basic skills that were also needed during the vignette task that was employed to assess children's interpretations and attributions of physical symptoms. The finding that cognitive development explained variance independent of age [12] has to do with individual differences in TOM skills. That is, while age to a large extent determines the ability to understand physical symptoms, some children have a more advanced theory-of-mind as compared to their contemporaries, which makes them even better in this respect.

Meanwhile, it should be noted that the percentage of explained variance of the vignette variables was rather small (i.e., 18\%), which suggests that children's capacity for making anxiety-related interpretations and internal attributions of physical symptoms is also determined by other factors than age and cognitive development. Two remarks are in order with regard to this observation. First, it can be argued that the theory-of-mind test only maps a small proportion of children's cognitive skills, and that the inclusion of another index of cognitive development (e.g., tests of language skills or intelligence) would have explained a larger percentage of the variance in children's interpretation and attribution scores. Second, when speculating about alternative factors involved in children's anxiety knowledge and interpretation, one likely candidate pertains to learning experiences. That is, children who have experienced physical symptoms due to illness, witnessed family members with such symptoms, and/or obtained information about symptoms via television and interactions with parents and peers, probably gain better understanding of physical symptoms, and might have an increased ability of linking them to emotional states such as anxiety [25].

External attributions were fairly stable across the three age groups, and not affected by cognitive development, which means that all children in this study did equally well in explaining physical symptoms in terms of external threats. A vast amount of studies have shown that anxious children display an interpretation bias, which means that they disproportionally impose danger interpretations upon ambiguous situations [26]. With this in mind, one might have predicted to find a relationship between general anxiety levels and children's external attribution scores, which as shown by the regression analysis presented in Table 4 appeared not to be the case. This result can be explained by means of the content of the vignettes. That is, the frequency of external attributions was in general fairly low (i.e., on average only 1 out of 10 vignettes was associated with an external threat), which seems to point out that vignettes were neutral rather than ambiguous.

Anxiety sensitivity was also assessed in this study, and generally yielded the expected results. To begin with, anxiety sensitivity made a small but significant positive contribution to anxiety-related interpretation and internal attribution scores, which means that children with higher fear of physical symptoms levels more often made anxiety-related 
interpretations and internal attributions. This result is in agreement with previous research [27], and indicates that high anxiety sensitive youths tend to process information about physical symptoms in a more threatening way [28]. Further, a negative relation was found between anxiety sensitivity and age/cognitive development [29], which suggests thatwith increasing age and cognitive skills - children normally report less fear of physical symptoms, probably because they have gained a better understanding of what these symptoms signify. Finally, anxiety sensitivity was also positively related to general anxiety levels as measured by a parent version of the PAS-R, which is in keeping with what has generally been found in the literature [19, 30, 31]. The fact that this link was relatively small in magnitude might be due to the fact that anxiety sensitivity and general anxiety were assessed by different informants (children and parents, respectively) [29].

It should be admitted that the current study suffers from various limitations. First, the investigation relied on a cross-sectional design. Although the results yielded suggestive information on age trends in children's anxiety-related interpretations and internal attributions of physical symptoms, a longitudinal set-up in which children are followed for several years would provide a more detailed picture of the developmental course of these phenomena. Second, while data of almost 400 children were collected for this study, one should keep in mind that the response rate was less than $45 \%$, thereby questioning the representativeness of the present sample. Third, most variables (i.e., anxious interpretations/attributions of physical symptoms, anxiety sensitivity, cognitive development) in this study were only assessed by means of children's self-report. Moreover, these measures were obtained by means of interview, which is a method that is susceptible to response bias. Hence it would have been preferable if we had also included parent-based measures, and this seems especially true considering the young participants that were included in this research. Finally, one could question the validity of the vignette paradigm for measuring anxiety-related interpretations and internal attributions of physical symptoms. To begin with, the vignettes involved others, and hence it can be argued that children's responses to these brief scenarios do not really tell us about the possible negative implications for themselves. Moreover, it may well be the case that this method is confounded by another cognitive factor, namely perspective taking. Therefore, an examination of children's responses to idiosyncratic physical symptoms (e.g., during a hyperventilation or $\mathrm{CO}_{2}$ challenge) would certainly be an improvement in this regard, but might also be problematic from an ethical point-of-view.

\section{Summary}

In spite of these shortcomings, the present study yields valuable information that nicely fits with results from previous research on the development of youths' cognitive responses to anxiety-related physical symptoms [14] and even extends this work by investigating younger children. Results indicated that age, cognitive development, and anxiety sensitivity were all positively related to children's ability to perceive physical symptoms as a signal of anxiety and making internal attributions. Most importantly, a substantial proportion of the children younger than 7 years was able to make a valid anxiety-related interpretation of a physical symptom, but very few were capable of making an internal attribution. This suggests that only after age 7 most young people meet the cognitive prerequisites for developing panic-like symptoms, and this implies that from that age physical symptoms-based theories of childhood anxiety can be readily applied [10]. 
Acknowledgments Children, parents, and staff of primary schools "De Tweestroom" in HendrikIdo-Ambacht, "De Klimroos" in Roosendaal, and "De Ark", "Het Visnet", and "Prins Willem Alexander" in Vlaardingen are kindly thanked for their participation in the current study.

Open Access This article is distributed under the terms of the Creative Commons Attribution Noncommercial License which permits any noncommercial use, distribution, and reproduction in any medium, provided the original author(s) and source are credited.

\section{Appendix}

Example of a vignette/black-and-white drawing that was employed to assess children's anxiety-related interpretations and attributions of physical symptoms (depending on the gender of the child, the main character is male or female).

Sam walks with his/her friends to the playground.

While walking, he/she notices that his/her heart is beating fast.



\section{References}

1. Rapee RM, Schniering CA, Hudson JL (2009) Anxiety disorders during childhood and adolescence: origins and treatment. Ann Rev Clin Psychol 5:311-341

2. Costello EJ, Mustillo S, Erkanli A, Keeler G, Angold A (2003) Prevalence and development of psychiatric disorders in childhood and adolescence. Arch Gen Psychiatry 60:837-844

3. Cartwright-Hatton S, McNicol K, Doubleday E (2006) Anxiety in a neglected population: prevalence of anxiety disorders in pre-adolescent children. Clin Psychol Rev 26:817-833

4. Muris P, Broeren S (2009) Twenty-five years of research on childhood anxiety disorders: publication trends between 1982 and 2006 and a selective review of the literature. J Child Family Studies 18: 388-395 
5. Lang PJ (1985) The cognitive psychopathology of emotion: fear and anxiety. In: Tuma AH, Maser JD (eds) Anxiety and the anxiety disorders. Erlbaum, Hillsdale, pp 131-170

6. Clark DM (1986) A cognitive approach to panic. Behav Res Ther 24:461-470

7. Reiss S, Peterson RA, Gursky DM, McNally RJ (1986) Anxiety sensitivity, anxiety frequency, and the prediction of fearfulness. Behav Res Ther 24:1-8

8. Ollendick TH, Birmaher B, Mattis SG (2004) Panic disorder. In: Morris TL, March JS (eds) Anxiety disorders in children and adolescents. Guilford, New York, pp 189-211

9. Hayward C, Killen JD, Kraemer HC, Taylor CB (2000) Predictors of panic attacks in adolescents. J Am Acad Child Adolesc Psychiatry 39:207-214

10. Nelles WB, Barlow DH (1988) Do children panic? Clin Psychol Rev 8:359-372

11. Muris P, Hoeve I, Meesters C, Mayer B (2004) Children's perception and interpretation of anxietyrelated physical symptoms. J Behav Ther Exp Psychiatry 35:233-244

12. Muris P, Mayer B, Vermeulen L, Hiemstra H (2007) Theory-of-mind, cognitive development, and children's interpretation of anxiety-related physical symptoms. Behav Res Ther 45:2121-2132

13. Muris P, Vermeer E, Horselenberg R (2008) Cognitive development and the interpretation of anxietyrelated physical symptoms in 4-13-year-old non-clinical children. J Behav Ther Exp Psychiatry 39: 73-86

14. Mattis SG, Ollendick TH (1997) Children's cognitive responses to the somatic symptoms of panic. J Abn Child Psychol 25:47-57

15. Flavell JH, Miller PH, Miller SA (2002) Cognitive development, 4th edn. Prentice Hall, Upper Saddle River

16. Bibace R, Walsh ME (1980) Development of children's concepts of illness. Pediatrics 66:912-917

17. Muris P, Steerneman P, Meesters C, Merckelbach H, Horselenberg R, Van den Hogen T, Van Dongen L (1999) The TOM-test: a new instrument for assessing theory of mind in normal children and children with pervasive developmental disorders. J Autism Dev Dis 29:67-80

18. Muris P, Meesters C, Mayer B, Bogie N, Luijten M, Geebelen E, Bessems J, Smit C (2003) The Koala Fear Questionnaire: a standardized self-report scale for assessing fears and fearfulness in pre-school and primary school children. Behav Res Ther 41:597-617

19. Silverman WK, Fleisig W, Rabian B, Peterson R (1991) Childhood anxiety sensitivity index. J Clin Child Psychol 20:162-168

20. Edwards SL (2007) Temperament and environmental risk factors contributing to anxiety symptoms in preschool-aged children. Macquarie University, Sydney, Australia, Unpublished Ph.D. thesis

21. Spence SH, Rapee RM, McDonald C, Ingram M (2001) The structure of anxiety symptoms among preschoolers. Behav Res Ther 39:1293-1316

22. Broeren S, Muris P (2008) Psychometric evaluation of two new parent-rating scales for measuring anxiety symptoms in young Dutch children. J Anx Dis 22:949-958

23. Piaget J (1970) Piaget's theory. In: Mussen PH (ed) Carmichael's manual of child psychology, vol 1. Wiley, New York, pp 703-732

24. Siegler RS (1996) Emerging minds: the process of change in children's thinking. Oxford University Press, New York

25. Muris P, Merckelbach H, Meesters C (2001) Learning experiences and anxiety sensitivity in normal adolescents. J Psychopathol Behav Assessm 23:279-283

26. Muris P, Field A (2008) Distorted cognition and pathological anxiety in children and adolescents. Cogn Emotion 22:395-421

27. Schneider S, In-Albon T, Rose U, Ehrenreich JT (2006) Measuring panic interpretation bias using the Anxiety Interpretation Questionnaire for Children. J Cogn Psychother 20:85-96

28. Reiss S, Silverman WK, Weems CF (2001) Anxiety sensitivity. In: Vasey MW, Dadds MR (eds) The developmental psychopathology of anxiety. Oxford University Press, London, pp 92-111

29. Weems CF, Taylor LK, Marks A, Varela RE (in press) Anxiety sensitivity in childhood and adolescence: parent reports and factors that influence associations with child reports. Cogn Ther Res

30. Rabian B, Peterson R, Richters J, Jensen PS (1993) Anxiety sensitivity among anxious children. J Clin Child Psychol 22:441-446

31. Weems CF, Hammond-Laurence K, Silverman WK, Ginsburg GS (1998) Testing the utility of the anxiety sensitivity construct in children and adolescents referred for anxiety disorders. J Clin Child Psychol 27:69-77 